DÍEZ MORRÁS, F.J., «Indefinición del interés superior del menor extranjero no acompañado en perjuicio de su protección», REDUR Io, diciembre 20I2, págs. 95-I04. ISSN I695-078X

\title{
INDEFINICIÓN DEL INTERÉS SUPERIOR DEL MENOR EXTRANJERO NO ACOMPAÑADO EN PERJUICIO DE SU PROTECCIÓN*
}

\author{
FCo. Javier DÍEZ MORRÁS
}

ABOGADO

PROFESOR ASOCIADO DE DERECHO INTERNACIONAL PRIVADO

UNIVERSIDAD DE LA RIOJA

SUMARIO: I. Los menores extranjeros no acompañados. II. Normativa internacional. III. Los menores extranjeros no acompañados en España. IV. La jurisprudencia del Tribunal Europeo de Derechos Humanos (TEDH). V. Conclusión. VI. Bibliografía.

RESUMEN: Los extranjeros menores de edad no acompañados son sujetos que requieren una especial protección jurídica debido a su vulnerabilidad. Con el fin de dar contenido al principio interés superior del menor es necesaria una unificación legislativa comunitaria que permita clarificar su significado en aras de la protección de esos menores. La jurisprudencia del Tribunal Europeo de Derechos Humanos comienza a marcar una línea por la que deberían seguir los legisladores europeos y que ayudaría a garantizar una mayor protección de los menores que llegan a Europa en situación de desamparo.

Palabras ClaVE: menores extranjeros no acompañados, interés superior del menor, Tribunal Europeo de Derechos Humanos.

ABSTRACT: Unaccompanied child migrants are individuals requiring special legal protection by virtue of their vulnerability. In order to provide the principle of the best interest of the minor with content, there is a need for a unification of European law aimed at clarifying its meaning to strengthen the protection of minors. The case law of the European Court of Human Rights is establishing the guidelines European legislators should follow to guarantee the greatest protection to minors arriving in Europe in distressed situations.

KEYwORDS: unaccompanied child migrants, best interest of the minor, European Court of Human Rights.

\section{Los menores extranjeros no acompañados}

La inmigración ha tenido en los últimos tiempos en España una incidencia social y económica extraordinaria en comparación con los países de nuestro entorno europeo. La

\footnotetext{
* Comunicación en el Congreso Nacional Protección jurídica, responsabilidad penal y mediación en justicia de menores, Logroño, I2 a I6 de diciembre de 20II, Departamento de Derecho, Universidad de La Rioja.
} 
irrupción en apenas quince años de un número considerable de extranjeros llegados básicamente para incorporarse al mercado laboral, ha generado en el país una serie de desafíos que hasta hace unos años no se habían planteado.

Uno de ellos ha sido la llegada de menores extranjeros no acompañados (MENAS) por sus progenitores $u$ otras personas legalmente autorizadas para responsabilizarse de ellos y, en menor medida, la presencia de otros menores que han llegado legalmente acompañados pero que posteriormente, y ya en nuestro país u otro de la Unión Europea, han sido abandonados.

Esta llegada paulatina pero continua a través de España, frontera sur de Europa, genera hoy una serie de cuestiones y problemas en los países comunitarios que afectan no sólo al menor y a su desprotección, sino también a las competencias entre las propias Administraciones ${ }^{\mathrm{T}}$.

De acuerdo con el Alto Comisionado para los Refugiados de las Naciones Unidas, hemos de entender por menores extranjeros no acompañados a los menores de dieciocho años que se encuentran fuera de su país de origen y están separados de sus padres o cuidadores habituales. Por otra parte el Comité de los Derechos del Niño de las Naciones Unidas los define como «los menores que están separados de ambos padres y otros parientes y no están al cuidado de un adulto al que, por ley o costumbre, incumbe esa responsabilidad» ${ }^{2}$.

En el mismo sentido, para el ámbito del Derecho Comunitario son menores no acompañados los menores de dieciocho años, nacionales de terceros países o apátridas, que llegan al territorio de los Estados miembros de la Unión Europea sin ir acompañados de un adulto responsable de ellos, ya sea legalmente o con arreglo a la costumbre, en tanto no se encuentren efectivamente bajo el cuidado de tal adulto responsable. No obstante también lo son aquellos menores a los que se deje solos tras su entrada en los Estados miembros. Esta noción se recogió en la Resolución del Consejo de la Unión Europea de 26 de junio de I997, relativa a los menores no acompañados nacionales de países terceros ${ }^{3}$ y posteriormente en las Directivas del Consejo de la Unión Europea 200I/55/CE, 2003/9/CE y $2003 / 86 / \mathrm{CE}^{4}$.

Los MENAS, por lo general, llegan a Europa con la clara intención de abandonar sus ámbitos de origen e instalarse de forma permanente, o por lo menos indefinida, en un país europeo con el fin de acceder a un modo de vida digno, en definitiva, a un puesto de trabajo, en una muestra de un claro desconocimiento de los sistemas de acceso al mercado laboral en los países de la Unión Europea y sus extrictas exigencias legales 5 .

En la década de I980 se experimentó en Europa un aumento significativo de la llegada de menores no acompañados, viéndose el fenómeno como un problema. Los países europeos adoptaron entonces una posición proteccionista que fomentaba un amparo directo

\footnotetext{
' «Andalucía acusa a Canarias de enviarle menores inmigrantes de forma irregular», El País, jueves 5 de agosto de 20ıо; «Europa quiere deportar a niños afganos», Público, martes I7 de agosto de 2010 .

${ }^{2} \mathrm{CRC} / \mathrm{GC} / 2005 / 6$, I de septiembre de 2005 .

${ }^{3}$ 97/C 22I/03, DOCE, n C 221, de i9 de julio de I997.

${ }^{4}$ Directiva 200I/55/CE del Consejo, de 20 de julio de 200I relativa a las normas mínimas para la concesión de protección temporal en caso de afluencia masiva de personas desplazadas y a medidas de fomento de un esfuerzo equitativo entre los Estados miembros para acoger a dichas personas y asumir las consecuencias de su acogida; $2003 / 9 / C E$ del Consejo, de 27 de enero de 2003 por la que se aprueban normas mínimas para la acogida de los solicitantes de asilo en los Estados miembros y 2003/86/CE, del Consejo, de 22 de septiembre, sobre el derecho a la reagrupación familiar.

${ }^{5}$ La política de acogida, repatriación y acuerdos para la integración de los menores extranjeros no acompañados. España, Red Europea de Migraciones-Punto de Contacto Nacional, Gobierno de España, 2009, págs. 9, 2I-25.
} 
por parte de la Administración de dichos Estados ${ }^{6}$. La entrada no ha decrecido y en 2003, a pesar de la dificultad de su cuantificación, se estimaba que en Europa había unos 32.I63 menores, siendo los principales países receptores España7, Italia y Gran Bretaña ${ }^{8}$.

Se pueden establecer dos grandes modelos de actuación con los MENAS en los países europeos:

- Los países que los contemplan como solicitantes de asilo, a los cuales se les aplica la legislación correspondiente: Portugal, Francia, Suiza, Bélgica, Holanda, Dinamarca e Irlanda.

- Los que los incluyen en el colectivo de inmigrantes irregulares, aplicándoseles la legislación interna relativa a la protección de menores: España, Italia.

Por otro lado es necesario señalar que la migración de menores de edad tiene distintas causas, en gran medida paralelas a la migración de adultos, siendo las principales las siguientes:

- Existencia en los países de origen de guerras, enfrentamientos étnicos, religiosos y políticos, y un ambiente social de violencia constante.

- Escaso desarrollo económico de esos mismos países sin una industrialización asentada y desarrollada, lo que ha llevado a Estados empobrecidos y sin estructuras políticas, administrativas, judiciales y laborales sólidas. familiares.

- Deseo de una mejora de las condiciones económicas y de vida particulares y/o

Finalmente es importante tener en cuenta cuáles son los países por los que se produce la entrada de los menores a Europa, siendo España e Italia dos de los principales en la actualidad. Tienen especial relevancia la cercanía geográfica, los lazos históricos y lingüísticos, la preexistencia de vínculos familiares o de amistad y las políticas migratorias y sociales de cada país. Por otra parte, con respecto al sexo y edad, los menores suelen ser varones de entre 9 y I8 años, si bien teniendo en cuenta su origen varían sus características.

Las zonas de mayor procedencia son el África Subsahariana, el Magreb y Europa del Este ${ }^{\mathrm{IO}}$. Los llegados del Magreb lo hacen desde la periferia de las grandes ciudades y de zonas rurales. En este último caso hay que hacer especial referencia al peso que la familia tiene a la hora de decidir la salida del menor en busca de un proyecto económico y vital nuevo. Estas familias pertenecen a clases sociales bajas y con escaso acceso a bienes y servicios básicos, o muy precarios, y normalmente llegan a Europa por España. En cuanto a los procedentes del Este europeo, especialmente en los últimos años desde Albania, suelen acceder en primer lugar a países como Italia. La motivación es básicamente económica, buscando oportunidades en la sociedad occidental. En Francia se ha observado el caso de asiáticos, especialmente chinos y de ambos sexos, de edades cercanas a la mayoría de edad.

\footnotetext{
${ }^{6}$ Quiroga, V. Y Doncel, C (Coords.), Rutas de pequeños sueños. Los menores migrantes no acompañados en Europa, Proyecto Con Red, 2005, págs. 35 y ss.

7 LÁZARo GonZÁlez, I., «Menores extranjeros no acompañados. La situación en España», Prolegómenos. Derechos $y$ valores, vol. X, nº. I9, 2007.

${ }^{8}$ Quiroga y Doncel (Coords.), Rutas de pequeños sueños $\cdots$, cit., págs. 5I-52.

${ }^{9}$ Idem, págs. 68 y ss.

Io Idem, pág. 54 .
} 
Su motivación está ligada muchas veces a la obtención de una formación académica, si bien tienen que trabajar inicialmente para pagar el viaje ${ }^{\mathrm{II}}$.

\section{Normativa internacional}

La regulación internacional de la situación-protección del menor de edad no acompañado que se encuentra fuera de su país de origen pivota sobre el concepto jurídico interés superior del menor. Este interés superior, en principio, se identifica por parte de la doctrina y la jurisprudencia nacional e internacional con la reagrupación familiar en el país de origen ${ }^{\mathrm{I} 2}$. El menor no acompañado es, en el país de destino, un extranjero en situación irregular y, tal y como se contempla en el caso español, puede ser repatriado a su país.

La Declaración de los Derechos del Niño de I959 no se refiere de forma expresa a los menores extranjeros no acompañados si bien establece en su artículo $2^{\circ}$ que «El niño gozará de una protección especial y dispondrá de oportunidades $y$ servicios, dispensado todo ello por la ley $y$ por otros medios, para que pueda desarrollarse física, mental, moral, espiritual $y$ socialmente en forma saludable y normal, así como en condiciones de libertad $y$ dignidad. Al promulgar leyes con este fin, la consideración fundamental a que se atenderá será el interés superior del niño». Esta es la primera manifestación en un instrumento internacional del principio conocido como interés superior del menor, principio fundamental que debe regir el ámbito de protección de los derechos del menor de edad.

La Convención de Naciones Unidas sobre los Derechos del Niño, de 20 de noviembre de 1989, ratificada por todos los países excepto Somalia y Estados Unidos, es hoy el instrumento internacional fundamental en cuanto a la protección de los menores no acompañados al ser de obligado cumplimiento para los países que lo han ratificado ${ }^{\mathrm{r} 3}$. Por otro lado es necesario hacer mención a un importante documento derivado de esta Convención y que sirve como orientación a los países firmantes, se trata de la Observación General $n^{\circ} 6$ del Comité de Derechos del Niño, de 2005, sobre el trato de los menores no acompañados y separados de su familia fuera de su país de origen ${ }^{\text {I4 }}$.

En la Convención se recogen cuatro grandes principios relacionados con los menores ${ }^{15}$, el principio de no discriminación (Art. 2), el derecho a la vida y al desarrollo (Art. 6), el principio de participación o derecho del menor a ser escuchado (Art. I2) y el principio del interés superior del menor, si bien la propia Convención no llena de contenido este último principio. Dice así: «En todas las medidas concernientes a los niños que tomen las instituciones públicas o privadas de bienestar social, los tribunales, las autoridades administrativas o los órganos legislativos, una consideración primordial a que se atenderá será el interés superior del niño» (Art. 3).

Por otro lado en su artículo 9.I establece la misma Convención que «Los Estados Parte velarán porque el niño no sea separado de sus padres contra la voluntad de éstos, excepto cuando, a reserva de revisión judicial, las autoridades competentes determinen, de conformidad

\footnotetext{
${ }^{\text {II }}$ Idem, págs. 62 y ss.

${ }^{12}$ PÉREZ, M. C., «Interés superior del menor y retorno de los menores no acompañados a su país de origen», II Jornadas sobre políticas migratorias, justicia y ciudadanía, CSIC, 2008.

${ }^{13}$ Senovilla Hernández, D., El tratamiento de los menores extranjeros no acompañados y separados en Europa. Un estudio comparado de seis países, Universidad Pontificia Comillas, tesis doctoral inédita, 20Io, pág. 24.

${ }^{14} \mathrm{CRC} / \mathrm{GC} / 2005 / 6$, de I de septiembre de 2005.

${ }^{15}$ Para entrar en el análisis de los contenidos de la Convención ver por ejemplo: Hodgkin, R. \& NEwELL, P., «Manual de aplicación de la Convención sobre los derechos del niño», Ginebra, UNICEF, 2004; CALVo GARCíA, M. y FernÁndEZ Sola, N. (coords.), «Los derechos de la infancia y la adolescencia», Zaragoza, Mira Editores, 2000; DetRICK, S., «A commenary on the Unied Nations Convention on the Rights of the Child», The Hague, Boston, Martinus Nijhoff Publishers, I999.
} 
con la ley y los procedimientos aplicables, que tal separación es necesaria en el interés superior del niño». En el apartado 3 del mismo artículo continúa señalando que se deberá respetar el derecho del niño separado de sus padres a mantener relaciones personales y contacto directo con ellos regularmente «salvo si ello es contrario al interés superior del niño».

El Comité de Derechos del Niño indica que el objetivo de su Observación General es ofrecer una solución duradera para el menor extranjero no acompañado, la cual comienza con el estudio de las posibilidades de reagrupación familiar ${ }^{16}$. Sin embargo el mismo Comité señala que en virtud del interés superior del menor se puede prolongar la separación de la familia y que la repatriación ha de ponerse en relación con otras posibilidades duraderas como pueden ser las de permanecer en el país de acogida, o en otro tercero. En fin, la Observación General no une interés del menor y solución duradera ${ }^{\mathrm{T}}$.

Ante lo anterior nos encontramos con un claro problema, pues la Convención no concreta el contenido del interés superior aplicado a los menores extranjeros no acompañados, por lo que redunda en su carácter de concepto jurídico indeterminado. De acuerdo con Senovilla Hernández, el principio del interés superior del menor recogido en la Convención sería una garantía de la vigencia de los demás principios recogidos en ella, supeditándose nuestro principio «a que en sus acciones [los Estados] garanticen positivamente el resto de derechos de la Convención $»^{18}$.

Aunque tanto la Convención como la Observación General no concretan el contenido del principio, de acuerdo con la interpretación llevada a cabo por Rozzi sobre la Observación General, el interés superior del menor debe estar vinculado a una solución duradera para ese menor ${ }^{19}$, ya sea optando por su reagrupación a su ámbito familiar de origen, su entrega a los servicios sociales de su país de origen, o la protección e integración en el país de acogida. La Observación General, en su párrafo 79, señala en concreto que se ha de buscar una solución duradera que resuelva las necesidades de protección y lleve a resolver la situación del menor no acompañado. Así, establecer una solución duradera debe ser el objetivo final de las regulaciones sobre la los menores no acompañados.

En principio el Comité de los Derechos del Niño, en base a los artículos 9 y io de la Convención, entiende que la reagrupación debe ser la solución duradera prioritaria ${ }^{20}$, si bien la propia Convención vimos que en su artículo 9 señala que excepto cuando «las autoridades competentes determinen... que tal separación es necesaria en el interés superior del niño». Un examen individual del caso llevará por tanto a determinar la solución duradera adecuada al menor. La Observación General recomienda que la reagrupación familiar no debe llevarse a cabo si hay un riesgo razonable de violación de los derechos del menor ${ }^{2 \mathrm{I}}$.

La aplicación directa, o a través de la legislación interna de cada país, de la Convención, es en realidad muy limitada debido al carácter no vinculante de la Observación General citada. Esto lleva a situaciones variadas y muchas veces alejadas del interés del menor entre los países adheridos a la Convención. La consecuencia en muchos casos es que los menores permanecen en los servicios de protección y una vez adultos pasan a la

\footnotetext{
${ }^{16}$ Comité de los Derechos del Niño, Observación General n 6, págs. 79-90.

${ }^{17}$ Senovilla, El tratamiento..., cit, pág. 29.

${ }^{18}$ Idem, pág. 29.

I9 RozZI, E., «The evaluation of the best interests of the child in the choice between remaining in the host country and repatriation: a reflection based on the Convention on the Rights of the Child», Save the Children Italy, 2002.

${ }^{20}$ Comité de los Derechos del Niño, Observación General n 6, 2005, párrafo 79.

${ }^{21}$ Idem, párrafo 82.
} 
irregularidad. En otras ocasiones continúan su viaje a ninguna parte de forma independiente y carente de protección jurídica ${ }^{22}$.

La Carta Europea de Derechos del Niño, de I992, no hace referencia a los menores extranjeros no acompañados ${ }^{23}$. Mayor importancia para el tema que nos ocupa tiene la Resolución del Consejo de la Unión Europea, de 26 de junio de I997, sobre menores no acompañados de terceros países, si bien, aunque recoge los principios de universalidad e interés superior de la Convención, dicho instrumento no tiene fuerza vinculante, por lo que minora su efectividad. Esta Resolución establece unas directrices para los países miembros $y$, con una literatura poco acertada que incide en la escasa fuerza coercitiva del texto, dice «que deberán tenerlas en cuenta $y$ esforzarse en incorporarlas a su derecho interno». La resolución posee además una «contradictoria doble vocación preventiva y protectora», según Senovilla ${ }^{24}$.

La Carta de los Derechos Fundamentales de la Unión Europea, de 7 de diciembre de 2000 y enmendada en 2007 , recoge en su artículo 24 los derechos del menor repitiendo aquellos principios y derechos de la Convención de las Naciones Unidas de I989. Dicha Carta, con la entrada en vigor del Tratado de Lisboa el I de diciembre de 2009, adquiere la misma fuerza vinculante que el resto de los Tratados. Los derechos que se corresponden con los recogidos en el Convenio Europeo para la Protección de los Derechos Humanos y Libertades Fundamentales (CEDH), son interpretados de acuerdo con el mismo Convenio. Especial relevancia adquiere el principio de interés superior del menor, que será singularmente considerado por las instituciones en lo que afecte a los menores, reconociéndose la unidad familiar salvo que el interés superior del menor aconseje lo contrario.

La Unión Europea vio finalmente en 20Io, bajo la presidencia de España, la necesidad de abordar nuevamente el complejo asunto de los menores extranjeros no acompañados. Así, el Consejo de Justicia y Asuntos del Interior de la Unión Europea sobre menores extranjeros no acompañados, en sus conclusiones de 3 de junio de 2010 incluye el reconocimiento de los derechos de los niños no acompañados y la necesidad de protegerlos, si bien esas conclusiones insisten en la devolución a sus países de origen. El Plan de acción sobre los menores no acompañados, que se llevará a cabo entre los años 2010 y 20I4, apunta que el objetivo del mismo es «ofrecer respuestas concretas a los desafíos que supone la llegada de un elevado número de menores $\cdots$ respetando al mismo tiempo los derechos del menor $y$ el principio del interés superior del menor» ${ }^{25}$.

Se puede afirmar que la regulación comunitaria hoy existente referida a los menores extranjeros no acompañados es exigua y no concreta ni da contenido satisfactorio al concepto jurídico interés superior del menor.

Es por ello el Tribunal Europeo de Derechos Humanos (TEDH) del Consejo de Europa, con sede en Estrasburgo, el órgano jurisdiccional fundamental en nuestro continente a la hora de conseguir una paulatina concreción de dicho concepto y por ende una protección adecuada de los derechos de los menores extranjeros no acompañados. Posee un sistema coercitivo propio por lo que su jurisprudencia es tenida en cuenta por los países miembros del Convenio Europeo para la Protección de los Derechos Humanos y Libertades Fundamentales, de 4 de noviembre de I950, sentando una doctrina fundamental.

\footnotetext{
${ }^{22}$ Senovilla, El tratamiento..., cit, pág. 62-76.

${ }^{23}$ DOCE, C 24I, de 2I de septiembre de I992.

${ }^{24}$ Idem, pág. I03.

${ }^{25} \mathrm{COM}$ (2010)2I3 final.
} 
Así quedó puesto de manifiesto con la sentencia de I2 de octubre de 2006 , caso Mubilanzila Mayeka y Kanini Mitunga contra Bélgica, analizada con detenimiento por Senovilla Hernández ${ }^{26}$, la cual se ha convertido en un verdadero referente en la protección de los derechos de los menores no acompañados. Su relevancia fue tal que provocó un importante cambio legislativo en el país condenado, Bélgica ${ }^{27}$.

En definitiva, y a la luz de la sentencia, la reagrupación familiar no será la única solución compatible con el interés del menor. No lo será por ejemplo en el caso en el que los propios familiares hayan incitado $u$ obligado a tomar la decisión de emigrar. Como ha señalado Pérez, una reagrupación le colocaría al menor en una situación inhumana y prohibida por el propio artículo 3 del Convenio Europeo de los Derechos Humanos ${ }^{28}$.

\section{Los menores extranjeros no acompañados en España}

La repatriación y reagrupación familiar se erige en la primera solución duradera por parte del legislador español, siendo uno de los asuntos clave relacionados con la protección jurídica de los MENAS en nuestro país a pesar de que, teniendo en cuenta por ejemplo la anterior sentencia del TEDH, no siempre es la opción más favorable al interés del menor ${ }^{29}$. No obstante, aunque la legislación contempla la repatriación y entrega al entorno familiar o a los servicios de protección de menores del país de origen como la opción preferente, ésta no es la única existente, pues también recoge la posibilidad de que el menor permanezca en España si no se dan las condiciones para su efectiva reagrupación, para una correcta tutela por los servicios de protección de su país de origen o existe riesgo para la integridad del menor. La identificación del interés superior del menor con la reagrupación familiar quedó legalmente establecida en 1996, mucho antes de que se manifestase en su más amplia dimensión la llegada de menores no acompañados a España, con la aprobación de la Ley Orgánica de Protección Jurídica del Menor ${ }^{3 \circ}$.

El artículo 35 de la Ley Orgánica 4/2000, de II de enero, sobre derechos y libertades de los extranjeros en España y su integración social, en su vigente redacción por Ley Orgánica 2/2009, de II de diciembre, se refiere de forma expresa a la situación de los menores no acompañados en España y a las posibilidades de actuación con los MENAS. En primer lugar España opta por la vía convencional para intentar evitar la llegada de estos menores a España mediante la firma de acuerdos internacionales con los países de origen, acuerdos que además deberán contemplar el retorno de esos menores. En virtud de las competencias que sobre menores poseen las Comunidades Autónomas, según la señalada ley, éstas también podrán firmar acuerdos con los países de origen en las cuestiones relacionadas con la atención e integración social ${ }^{3 \mathrm{I}}$. Como se aprecia en el punto 5 de dicho artículo, todas las actuaciones de las autoridades españolas tienen como finalidad la «iniciación de un procedimiento de repatriación» a su país de origen «o a aquel donde se encontrasen sus familiares o, en su defecto, sobre su permanencia en España». Es en ese

${ }^{26}$ Senovilla HernándeZ, D., «Comentario sobre la Sentencia del Tribunal Europeo de Derechos Humanos de Estrasburgo de I2 de octubre de 2006, caso Mubilanzila Mayeka y Kanini Mitunga contra Bélgica», Revista de Derecho Migratorio y Extranjería, Ed. LEX NOVA, I3, 2006, págs. I87-I99.

${ }^{27}$ Idem, pág. I96.

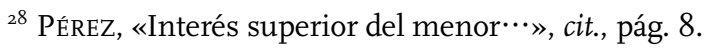

${ }^{29}$ LÁZARO GonZÁLEZ, «Menores extranjeros no acompañados $\cdots »$, cit., pág. 156.

${ }^{30}$ La Ley Orgánica I/I996, de I5 de enero, de Protección Jurídica del Menor recoge en el artículo in unos principios rectores de la actuación de la Administración en materia de protección de menores, entre los que se encuentra la supremacía del interés del menor y el mantenimiento de éste en su entorno familiar de origen, salvo que sea contra su interés.

${ }^{3 r}$ A día de hoy únicamente existen acuerdos firmados con Senegal y Marruecos, si bien en vigor sólo se encuentra el firmado con el primero de los dos países. 
mismo punto donde aparece por primera vez el término jurídico interés superior del menor al señalarse que, de acuerdo con ese principio, la repatriación se efectuará mediante la reagrupación familiar o mediante la puesta a disposición de los servicios de protección de menores del país de origen, si se dieran las condiciones adecuadas para su tutela por parte de esos servicios. En fin, el interés superior del menor se vincula no tanto a la posibilidad o no de mantener al menor en España en aras de su mejor protección, sino que el legislador español lo incluye en el ámbito de la repatriación y concretamente habrá que tenerlo en cuenta para valorar si es entregado a su familia o a los servicios públicos de su país.

El anterior reglamento de desarrollo de la ley, aprobado por Real Decreto $2.394 / 2004$, de 30 de diciembre, derogado en la actualidad, ya hacía referencia en su artículo 92.4 de forma clara a qué se debía entender como interés superior del menor en el contexto de los menores no acompañados al indicar que la «la repatriación a su país de origen solamente se acordará si se dieran las condiciones para la efectiva reagrupación familiar del menor, o para la adecuada tutela por parte de los servicios de protección de menores del país de origen». En parecidos términos se había pronunciado un mes antes a la aprobación del reglamento la Fiscalía General del Estado ${ }^{32}$. La importancia de la protección de los MENAS ha llevado a que el nuevo reglamento, aprobado por Real Decreto 557/20II, de 20 de abril, haya regulado en todo un capítulo (artículos I89 a I98) la situación de estos menores. En él se incide en la obligatoriedad de la repatriación, si bien contempla de nuevo la posibilidad de que ésta no se pueda llevar a cabo.

Sin embargo, como ha destacado Human Rights Watch, en España no existe una reglamentación específica, no determinándose correctamente ese interés superior del menor por la legislación, lo que ha llevado a repatriaciones que vulneran el interés del menor por no haberse realizado mediante la reagrupación a sus familias, o sin ser acogidos por los servicios de menores de sus países de origen ${ }^{33}$. Ha sido en sede judicial donde, de acuerdo con la jurisprudencia y legislación internacional, se ha llegado a dar contenido a ese principio. En España los Tribunales han valorado las decisiones de repatriación de menores anulándolas en numerosas ocasiones ${ }^{34}$.

\section{La jurisprudencia del Tribunal Europeo de Derechos Humanos (TEDH)}

El TEDH ha ido concretando el contenido del amplio e indefinido concepto interés superior del menor. El Convenio Europeo para la Protección de los Derechos Humanos y las Libertades Fundamentales otorga el derecho a todo ciudadano a recurrir ante este Tribunal si los derechos y libertades recogidos en aquel han sido violados.

Ya se ha señalado la especial importancia de este tribunal europeo por su fuerza vinculante y por tanto se erige en fundamental para la concreción y salvaguarda del principio señalado. A continuación se detallan un inicial grupo de sentencias especialmente relevantes para el tema que nos ocupa:

${ }^{32}$ Instrucción 6/2004, de 26 de noviembre, sobre tratamiento jurídico de menores extranjeros no acompañados: «la repatriación no es, sin embargo, un objetivo absoluto que se haya de perseguir a toda costa; pueden estar en juego también otros intereses, como la vida, la integridad física o psíquica y el respeto a los derechos fundamentales del menor, que pueden hacer que la balanza del interés superior del éste se incline finalmente en pro de su permanencia en nuestro país».

${ }^{33}$ Informe «Retornos a cualquier precio», Human Rights Watch, octubre 2008, pags. I y ss.; Defensor del Pueblo, «Informe Anual 2007», pág. 488.

34 STSJ-Madrid, de 26 de abril de 2007 , STSJ-Cantabria, de 3i de julio de 2007 , SJCA-Huesca, de I3 de octubre de 2006 , SSJCA-Madrid $n^{\circ}$ I5, de 22 de noviembre de 2006, 27 de abril de 2007 , de I de mayo de 2007 y 4 de marzo de 2008 , SJCA-Madrid $\mathrm{n}^{\circ} 26$, de 22 de octubre de 2007 , SJCA-Madrid, $\mathrm{n}^{\circ} 20$, de 4 de diciembre de 2007 . 
- Nsona c. Holanda, sentencia de 26 de junio y 26 de octubre de i996. Admite la legalidad del rechazo en frontera y el retorno de los menores a su país siempre que el menor esté atendido y no haya riesgo para su integridad.

- Bronda c. Italia, sentencia de 9 de junio de I998. Está justificada la separación del menor de su familia de origen.

- E. P. c. Italia, sentencia de I6 de noviembre de I999.

- Samy c. Holanda, sentencia de I8 de junio de 2002: Antes de iniciar un procedimiento de alejamiento de menores las autoridades deben asegurarse de la posibilidad de ejecutar la medida y evitar privaciones provisionales de libertad.

- D. c. Reino Unido y BB. c. Francia, sentencia de 7 de octubre de I998. En expulsiones de menores delincuentes hay que valorar que no puedan ser objeto de persecución, violación de derechos o malos tratos en su país.

- Benjamin Gnahoréc. Francia, sentencia de ig de septiembre de 2000.

- Boultifc. Suiza, septiembre de $200 \mathrm{I}$.

- Sen c. Holanda, 2I de diciembre de $200 \mathrm{I}$

- Tuquabo-Tekle and others c. Holanda, I de diciembre de 2005.

- Mubilanzila Mayeka y Kaniki Mitunga c. Bélgica, sentencia de I2 de octubre de 2006. La expulsión de una menor de edad supuso un trato inhumano y degradante por no haberse considerado la situación real que se iba a encontrar a su regreso.

- Maslov c. Austria, sentencia de 23 de junio de 2008. Joven delincuente de origen búlgaro que reside en Austria y es expulsado por la comisión de varios delitos. $\ 58$ y 82 (The Court considers that where offences committed by a minor underlie an exclusion order regard must be had to the best interests of the child... It underlined that the best interests and well-being of the children, in particular the seriousness of the difficulties which any children of the applicant were likely to encounter in the country to which the applicant was to be expelled, was a criterion to be taken into account when assessing whether an expulsion measure was necessary in a democratic society).

- Saadi c. Italia, sentencia de 28 de febrero de 2008 . No se debe devolver a nadie a su país de origen si se le expone a un riesgo de maltrato.

\section{Conclusión}

El interés superior del menor en relación con los menores extranjeros no acompañados, no es un concepto unívoco en Europa, pues se le da diferente contenido de acuerdo con el tiempo y las circunstancias políticas, sociales y jurídicas de cada Estado. No obstante la jurisprudencia del Tribunal Europeo de los Derechos Humanos ha ido perfilando el concepto jurídico indeterminado interés superior del menor, lo cual ayuda al establecimiento de una solución duradera para el menor extranjero no acompañado. Sin embargo la legislación comunitaria y la interna de los diferentes países de la Unión Europea no han otorgado aún un contenido más o menos definitivo al concepto en el contexto de las migraciones internacionales contemporáneas, con lo que se favorece la desprotección del menor de edad extranjero no acompañado que llega a Europa. 


\section{Bibliografía}

Calvo García, M y Fernández Sola, N. (coords.), «Los derechos de la infancia y la adolescencia», Zaragoza, Mira Editores, 2000.

Defensor del Pueblo, «Informe Anual 2007».

DETRICK, S., «A commenary on the Unied Nations Convention on the Rights of the Child», The Hague, Boston, Martinus Nijhoff Publishers, I999.

Hodgrin, R. \& Newell, P., «Manual de aplicación de la Convención sobre los derechos del niño», Ginebra, UNICEF, 2004 .

LÁZARo GonZÁlEZ, I., «Menores extranjeros no acompañados. La situación en España», Prolegómenos. Derechos Y valores, vol. X, $\mathrm{n}^{\circ}$. I9, 2007.

PÉREZ, M. C., «Interés superior del menor y retorno de los menores no acompañados a su país de origen», II Jornadas sobre políticas migratorias, justicia y ciudadanía, CSIC, 2008.

Quiroga, V. y Doncel, C. (Coords.), Rutas de pequeños sueños. Los menores migrantes no acompañados en Europa, Proyecto Con Red, 2005.

RozZI, E., «The evaluation of the best interests of the child in the choice between remaining in the host country and repatriation: a reflection based on the Convention on the Rights of the Child», Save the Children Italy, 2002.

Senovilla Hernández, D., «Comentario sobre la Sentencia del Tribunal Europeo de Derechos Humanos de Estrasburgo de I2 de octubre de 2006, caso Mubilanzila Mayeka y Kanini Mitunga contra Bélgica», Revista de Derecho Migratorio y Extranjería, Ed. Lex Nova, I3, 2006, páginas I87-I99.

Senovilla HeRnÁndez, D., El tratamiento de los menores extranjeros no acompañados y separados en Europa. Un estudio comparado de seis países, Universidad Pontificia Comillas, 2010, tesis doctoral inédita.

Informe «Retornos a cualquier precio», Human Rights Watch, octubre 2008

La política de acogida, repatriación y acuerdos para la integración de los menores extranjeros no acompañados. España, Red Europea de Migraciones-Punto de Contacto Nacional, Gobierno de España, 2009. 